\title{
Genotype-Specific Microsatellite (SSR) Markers for the Sugarcane Germplasm from the Karst Region of Guizhou, China
}

\author{
Yuhua Fu' ${ }^{1 * \#, ~ Y o n g b a o ~ P a n ~}{ }^{2 * \#, ~ C h a o y u n ~ L e i ~}{ }^{1}$, Michael P. Grisham², Chenglong Yang1, Qiuyi Meng1 \\ ${ }^{1}$ Guizhou Institute of Subtropical Crops, Guizhou Academy of Agricultural Sciences, Xingyi, Guizhou, China \\ ${ }^{2}$ Sugarcane Research Unit, Southeast Area, USDA-ARS, Houma, LA, USA \\ Email: *fufu6699@aliyun.com, *yongbao.pan@ars.usda.gov
}

How to cite this paper: Fu, Y.H., Pan, Y.B. Lei, C.Y., Grisham, M.P., Yang, C.L. and Meng, Q.Y. (2016) Genotype-Specific Microsatellite (SSR) Markers for the Sugarcane Germplasm from the Karst Region of Guizhou, China. American Journal of Plant Sciences, 7, 2209-2220.

http://dx.doi.org/10.4236/ajps.2016.715195

Received: October 13, 2016

Accepted: November 6, 2016

Published: November 9, 2016

Copyright $\odot 2016$ by authors and Scientific Research Publishing Inc. This work is licensed under the Creative Commons Attribution International License (CC BY 4.0).

http://creativecommons.org/licenses/by/4.0/

\begin{abstract}
Genetic variability among sugarcane genotypes from the Karst region of China was evaluated using genotype-specific microsatellite (SSR) markers. Eighteen sugarcane genotypes including 13 active cultivars and five elite QT-series clones bred locally were screened for genetic variability with 21 SSR primer pairs. All the primer pairs were highly polymorphic and amplified a total of 167 alleles with an average of eight alleles per primer pair. The average polymorphism information content (PIC) value was 0.86 with a range of 0.68 and 0.92 . A UPGMA dendrogram categorized the 18 sugarcane genotypes into three major groups containing three, ten and five genotypes, respectively. No geographical affinity was observed among genotypes within the same group. Eight SSR primer pairs produced cultivar-specific alleles, of which five alleles were unique to the QT-series clones, namely, SMC334BS-165 and SMC851MS-145 in QT 08-558, mSSCIR43-229 in QT 4, SM597CS-182 in QT 08-536 and SMC7CUQ-168 in QT 06-212. The clone-specific SSR alleles will be useful in identifying elite QT-series clones for use in the sugarcane crossing programs in China.
\end{abstract}

\section{Keywords}

Sugarcane, Clone-Specific SSR Markers, Genetic Diversity, Karst Region

\section{Introduction}

Modern sugarcane cultivars (Saccharum hybrids spp., $2 n=110-130$ ) are inter-specific, highly polyploid and aneuploid hybrid derivatives of a few progenitor Saccharum

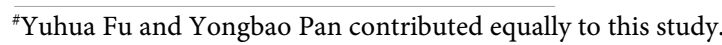


clones with a genome size of around 7.5 - $10 \mathrm{~Gb}$. Due to high level of heterozygosity and complexity of its genome, sugarcane molecular research has been confronted with unique challenges not encountered in other major crops, resulting in a slow progress in sugarcane molecular breeding. Nonetheless, many researchers have made an effort to evaluate different sources of sugarcane germplasm with various DNA markers, including 5S rRNA intergenic transcribed spacer (ITS) [1], restriction fragment length polymorphism (RFLP) [2] [3], random amplified polymorphic DNA (RAPD) [4] [5] [6] [7], amplified fragment length polymorphism (AFLP) [8] [9] [10], simple sequence repeats (SSR) [8] [11] [12] [13] [14], target region amplification polymorphism (TRAP) [15] [16], conserved-intron scanning marker (CISP) [17] [18] and single nucleotide polymorphism (SNP) [19] [20]. Sugarcane breeders have successfully found some cultivarspecific, species-specific and trait-specific DNA makers to accelerate the breeding process [13] [21] [22] [23] [24] [25].

Among PCR-based marker systems, SSR is a powerful marker system once developed for a particular organism due to its ubiquitous distribution across the entire genome, high polymorphism, and reliability. Molecular breeding scientists have successfully developed sugarcane SSRs including 221 genomic-SSRs developed by the International Sugarcane Microsatellite Consortium (ISMC) [11], 402 expressed sequence tags (EST)derived SSRs developed by da Silva [12], 837 EST-SSRs from SUCEST by Souza's group [25] [26] [27] [28] [29], and 702 SSRs mined from both genomic and expressed sequences by the Indian Agricultural Research Institute (IARI) [30]. Some of the sugarcane SSR markers were applied to paternity analysis [31], genetic diversity assessment [32] [33] [34], genetic linkage map construction [28] [35], germplasm evaluation and variety identity testing [13] [36]. In addition, SSR technology combined with capillary electrophoresis and fluorescence detection system shows better performance in genotyping analysis due to higher accuracy and detection power [36]. Pan et al. employed this detection system to successfully identify sugarcane clones that had been mis-labeled [37]. Recently, this detection system also enabled the segregation analysis of microsatellite (SSR) markers in sugarcane polyploids [38] [39].

Karst represents special landscape geographic regions formed from the dissolution of soluble rocks. China is one of the countries in the world with a large distribution of Karst landscape that can be further classified as tropical and sub-tropical Karst region, plateau Karst region, or mountain Karst region. Guizhou represents the typical plateau Karst landform in China with an average altitude of 1100 meters above the sea level. Sugarcane has been grown in Guizhou for more than 60 years, normally in the valley or on hilly slopes 375 - 900 meters above the sea level. In the local sugarcane growing area, the annual mean temperature is $17.0^{\circ} \mathrm{C}-20.2^{\circ} \mathrm{C}$, the average annual precipitation is $1200 \mathrm{~mm}$, and 345 - 365 days are frost-free. In 2013, sugarcane growing area was around 30,000 hectares in Guizhou alone, which was reduced gradually in the past two years due to lower sugar price in the market. Since the $19^{\text {th }}$ century, elite sugarcane germplasm has been introduced into Guizhou from other sugarcane research institutions in China as well as other countries for evaluation and selection. Approximately 20 
sugarcane cultivars are currently being used in Guizhou sugarcane production, of which, six cultivars account for more than $80 \%$ of the planted area in Guizhou; each with unique traits. For example, ROC21, ROC22 and ROC25 from Taiwan have overall good traits; YT 94-128 is early maturing and drought resistant; Xuan 50 has multitillers and thin stalks; and QT4 is a locally bred variety specifically for black sugar production.

The goal of this study was to evaluate the extent of genetic variability among the sugarcane germplasm involved in sugarcane breeding and production in Guizhou with highly polymorphic SSR primer pairs. The expected results will provide not only a better understanding of the genetic base of sugarcanes germplasm, but also useful information to assign cross parents for the breeding program in Guizhou.

\section{Materials and Methods}

\subsection{Plant Materials}

Eighteen sugarcane genotypes were involved in this study, including 13 cultivars that were widely grown for sugar production in Guizhou, China and five elite clones that were selected through conventional breeding by the Guizhou Institute of Subtropical Crops (GISC) (Table 1). Healthy apical leaves were collected from the plants of the 18 genotypes from the germplasm nursery at GISC, which were stored at $-20^{\circ} \mathrm{C}$ prior to DNA extraction. DNA isolation was conducted according to Pan et al. [1]. DNA concentrations were measured on a Shimadzu Model UV-1601 spectrophotometer (Shimadzu Scientific Instruments, Inc., Columbia, MD, USA) and DNA quality was assessed by $0.8 \%$ agarose gel electrophoresis using diluted uncut $\lambda$ DNA as the standard. Final DNA concentration was adjusted to five $\mathrm{ng} / \mu \mathrm{L}$ and stored at $-20^{\circ} \mathrm{C}$ for SSR analysis.

\subsection{SSR Primer, PCR, and Fragment Analysis}

SSR analysis was conducted with 21 highly polymorphic ISMC SSR primer pairs following the protocol of Pan [13]. PCR amplification reactions were conducted in a total volume of $10 \mu \mathrm{L}$, containing $10 \mathrm{ng}$ of DNA, $0.2 \mathrm{mM}$ each of FAM-labeled forward primer and unlabeled reverse primer, $80 \mathrm{mM}$ each of dNTP, $10 \mathrm{mM}$ Tris- $\mathrm{HCl}, 2.5 \mathrm{mM}$ $\mathrm{MgCl}_{2}, 50 \mathrm{mM} \mathrm{KCl}$, and $1 \mathrm{U}$ Taq DNA polymerase (Roche Molecular Biochemicals, Indianapolis, IN, USA). The thermo-cycle program was subsequently conducted as follows: $95^{\circ} \mathrm{C}$ for 5 mins, followed by 30 cycles of $94^{\circ} \mathrm{C}$ for $30 \mathrm{~s}$, annealing temperature for each pair of primers for $30 \mathrm{~s}, 72^{\circ} \mathrm{C}$ for $30 \mathrm{~s}$, followed by $72^{\circ} \mathrm{C}$ for 2 min. FAM-labeled PCR fragments along with the GS500 size standards were separated through capillary electrophoresis (CE) on the DNA Analyzer ABI 3730XL (Applied Biosystems, Foster City, CA, USA) to generate $<$.fsa $>$ GeneScan files.

\subsection{Data Analysis}

The GeneMapper software v3.0 (Applied Biosystems, Foster City, CA, USA) was used to analyze the GeneScan files through visualization of capillary electrophoregrams of 
Table 1. A list of sugarcane genotypes involved in the study.

\begin{tabular}{|c|c|c|}
\hline Name* & Origin & Pedigree \\
\hline FN38 & Fujian, China & Yuetang $83-257 \times$ Yuetang $83-271$ \\
\hline GT11 & Guangxi, China & $\mathrm{CP} 49-50 \times \mathrm{Co} 419$ \\
\hline GT27 & Guangxi, China & Yuetang 85-1622 × Yacheng 73-512 \\
\hline GT29 & Guangxi, China & Yacheng 94-46 × ROC22 \\
\hline GT31 & Guangxi, China & Yuetang 91-976 × ROC1 \\
\hline QT4 & Guizhou, China & Nco310 $\times$ CP36-105 \\
\hline ROC21 & Taiwan, China & $70-3792 \times \mathrm{ROC} 163$ \\
\hline ROC22 & Taiwan, China & ROC5 $\times 69-463$ \\
\hline ROC25 & Taiwan, China & $79-6048 \times 69-463$ \\
\hline YT00-236 & Guangdong, China & Yuenong 73-204 × CP 72-1210 \\
\hline YT60 & Guangdong, China & Yuetang 92-1287 × Yuetang 93-159 \\
\hline YT94-128 & Guangdong, China & Zhanzhe $80-101 \times$ ROC1 \\
\hline QT06-156 & Guizhou, China & ROC10 × CP 57-614 \\
\hline QT06-212 & Guizhou, China & $\mathrm{ROC} 10 \times \mathrm{CP} 57-614$ \\
\hline QT08-526 & Guizhou, China & ROC10 $\times$ Yacheng $84-125$ \\
\hline QT08-536 & Guizhou, China & ROC10 $\times$ Yacheng $84-125$ \\
\hline QT08-558 & Guizhou, China & Neijiang 00-118 × Guitang 94-119 \\
\hline Xuan 50 & Brazil & (Unknown) \\
\hline
\end{tabular}

${ }^{*} \mathrm{FN}=$ Funong; GT = Guitang; $\mathrm{QT}=$ Qiantang; ROC $=$ Taiwan, China; $\mathrm{YT}=$ Yuetang; Xuan $50=$ RB72-454.

SSR alleles with sizes automatically calibrated using the GS500 size standards. Irregular Peaks such as "stutters", "pull-ups", "dinosaur tails", and "minus-A peaks" were not scored according to Pan [13]. The presence of a regular peak was scored as 1 and its absence was scored as 0 . The polymorphism information content (PIC) of each SSR primer pair was calculated according to the formula of Milbourne et al. [40]: PIC = 1 $\Sigma \mathrm{Pg}^{2}$, where $\mathrm{Pg}$ is the frequency of an individual genotype. Genetic distance between each genotype was calculated using the Jaccard similarity coefficient and then a dendrogram was constructed using NTSYSpc-2.2 [41] software on the basis of unweighted pair group method with arithmetic means (UPGMA). A homology tree was built using DNAMAN $^{\circledR}$ (Lynnon Co., Quebec, Canada) to analyze the genetic homology relationship among the 18 sugarcane genotypes where the presence of a regular peak was recorded as A and its absence was recorded as C [42].

\section{Results and Discussion}

\subsection{Characteristics of SSR Polymorphism}

All sugarcane SSRs used in this study were polymorphic yielding a total of 167 alleles, of which 148 alleles (88.6\%) were polymorphic. Figure 1 is an example of SSR profiles 


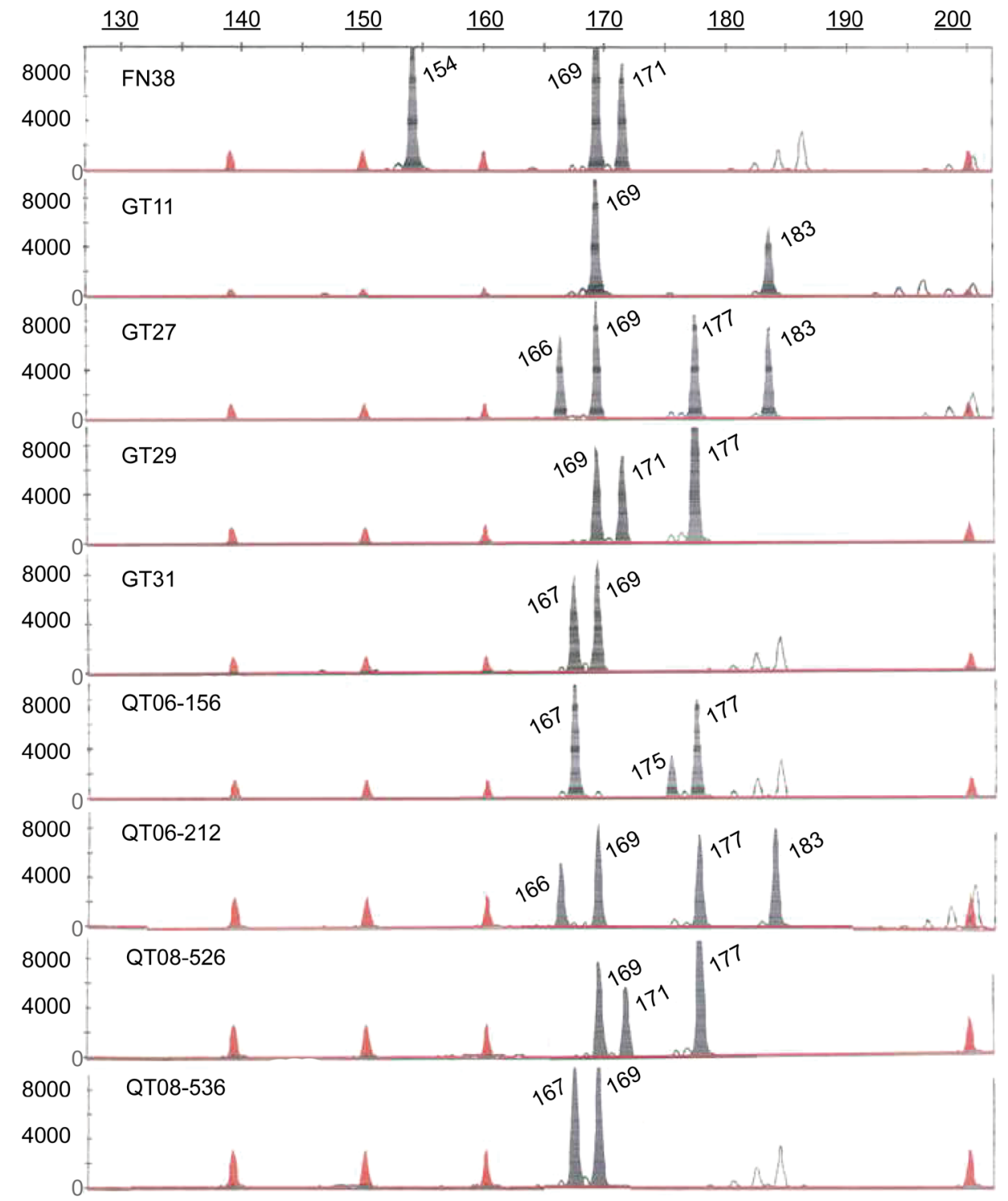

Figure 1. Discriminative SSR profiles of nine sugarcane genotypes produced by SSR primer pair SMC336BS. The Y-axis value represents the fluorescence strength or the relative yield of amplified DNA fragment. The X-axis value represents DNA fragment sizes in base pairs.

of nine sugarcane genotypes based on marker SMC336BS. The number of alleles produced by each SSR primer pair ranged from four to twelve with an average of eight alleles per primer pair (Table 2), slightly higher in comparison with Hameed's study (6.85) [43] but lower than the average number of alleles per primer pair reported by Chandra (9.2) [21] and Liang (15.6) [44] using the same set of SSR makers. SMC24DUQ and SMC597CS both produced maximum number of alleles, of which 10 were polymorphic. Although SMC486CG and SMC569CS produced the minimum number of alleles, all alleles were polymorphic. The percentage of polymorphic bands for each SSR primer pair was in the range of $66.7 \%$ and $100 \%$. Eight SSR primer pairs (38.1\%), namely, SMC278CS, SMC31CUQ, SMC334BS, SMC336BS, SMC486CG, 
Table 2. Genetic diversity among 18 sugarcane genotypes as revealed by SSR primer pairs.

\begin{tabular}{|c|c|c|c|c|}
\hline \multirow{2}{*}{ Primer Pair } & \multirow{2}{*}{ Total \# Bands } & \multirow{2}{*}{$\begin{array}{c}\text { \# Polymorphic } \\
\text { Bands (\%) }\end{array}$} & \multirow{2}{*}{ SSR Size Range (bp) } & \multirow{2}{*}{ PIC } \\
\hline & & & & \\
\hline SMC119CG & 10 & $9(90.0)$ & $106-228$ & 0.91 \\
\hline SMC1604SA & 8 & $7(87.5)$ & $106-127$ & 0.91 \\
\hline SMC18SA & 6 & $4(66.7)$ & $137-165$ & 0.82 \\
\hline SMC24DUQ & 12 & $10(83.3)$ & $126-151$ & 0.91 \\
\hline SMC278CS & 9 & $9(100)$ & $140-182$ & 0.91 \\
\hline SMC31CUQ & 9 & $9(100)$ & $138-179$ & 0.92 \\
\hline SMC334BS & 10 & $10(100)$ & $147-165$ & 0.92 \\
\hline SMC336BS & 10 & $10(100)$ & $141-187$ & 0.91 \\
\hline SMC36BUQ & 6 & $5(83.3)$ & $104-255$ & 0.86 \\
\hline SMC486CG & 4 & $4(100)$ & $225-242$ & 0.81 \\
\hline SMC569CS & 4 & $4(100)$ & $167-222$ & 0.78 \\
\hline SMC7CUQ & 7 & $571.4)$ & $158-172$ & 0.83 \\
\hline SMC597CS & 12 & $10(83.3)$ & $144-182$ & 0.91 \\
\hline SMC703BS & 7 & $5(71.4)$ & $202-220$ & 0.83 \\
\hline SMC851MS & 9 & $8(88.9)$ & $127-145$ & 0.9 \\
\hline mSSCIR66 & 7 & $7(100)$ & $127-156$ & 0.9 \\
\hline mSSCIR3 & 9 & $8(88.9)$ & $169-198$ & 0.88 \\
\hline SMC1751CL & 6 & $4(66.7)$ & $137-154$ & 0.68 \\
\hline SMC22DUQ & 7 & $6(85.7)$ & $147-163$ & 0.88 \\
\hline mSSCIR43 & 10 & $10(100)$ & $169-252$ & 0.91 \\
\hline mSSCIR74 & $\underline{5}$ & $4(80)$ & $217-229$ & 0.78 \\
\hline Total & 167 & 148 & & \\
\hline Mean & 8 & 7 & & 0.86 \\
\hline
\end{tabular}

SMC569CS, mSSCIR66, produced $100 \%$ polymorphic alleles. The PIC values of the 21 SSR primer pairs ranged from 0.68 to 0.92 with an average of 0.86 . SMC31CUQ and SMC334BS were the most informative primer pairs producing the highest PIC value of 0.92 .

Eight SSRs were found to be cultivar-specific for nine sugarcane genotypes, amplifying a total of 11 unique SSR alleles. Of which, five were specific to QT-series clones, namely, SMC851MS-145, mSSCIR43-229, SM597CS-182, SMC7CUQ-168, and SMC334BS-165. Primer pair SMC851MS produced three cultivar-specific alleles, namely, SMC851MS-127 in Xuan 50, SMC851MS-143 in FN 38, and SMC851MS-145 in QT 08-558. Primer pair mSSCIR43 produced two cultivar-specific alleles, namely, mSSCIR43-229 in QT 4 and mSSCIR43-240 in GT 31. Each of the remaining six SSR primer pairs amplified only one cultivar-specific allele, namely, SM597CS-182 in QT 
08-536, SMC7CUQ-168 in QT 06-212, SMC334BS-165 in QT 08-558, SMC24DUQ-151 in FN 38, SMC1604SA-106 in GT 11, and SMC119CG-223 in YT 60. These results implies that a fewer number of primer pair combinations among these eight SSR primer pairs will be able to identify sugarcane genotypes within a large scale of sugarcane germplasm evaluation. Moreover, these primer pairs are also primer pairs of choice for pedigree verification in sugarcane polycross or hybrid identification in bi-parental crosses when the nine sugarcane genotypes are used as the parents.

The performances of each SSR primer pair may vary on different sugarcane cultivars because these cultivars may have different chromosome makeups. The 21 SSR primer pairs used in the present study were chosen from 67 highly polymorphic SSR primer pairs based on the evaluation of five elite U.S. germplasm [13]. These primer pairs were able to distinguish among cultivars and breeding lines in the U.S. [42]. These SSR primer pairs also can detect genetic variations among sugarcane clones originated from China, Bangladesh, South Africa, Mexico, India, and related wild species [21] [44] [45]. Therefore, these 21 SSR primer pairs can be considered as core SSR primer pairs for sugarcane molecular characterization worldwide. However, Pan suggested that these SSR primer pairs be tested first on a local elite sugarcane germplasm collection developed under certain geographical environment prior to a full-scale genotyping exercise [13].

It is the first report on evaluating genomic diversity among sugarcane cultivars growing in Karst region in China, the 21 SSR primer pairs showed highly polymorphic among both material sugarcane and elite clones, which indicates these 21 SSR primer pairs are suitable for genotyping sugarcane clones bred in Karst climate in China.

\subsection{Genetic Diversity}

Homology analysis showed there were $64-98 \%$ homologies among the 18 sugarcane genotypes (Figure 2). Two pairs of genotypes, namely, ROC21 and YT 00-236 and YT 94-128 and ROC25, shared the highest homology value of 98\%, followed by ROC22 and YT-60 (97\%). The homology values shared between the QT-series sugarcane genotypes were between $67 \%$ and $76 \%$. A UPGMA dendrogram was constructed to reveal the extent of genetic diversity among the 18 sugarcane genotypes. Genetic similarity coefficients for all the genotypes ranged from 0.64 to 0.98 . The 18 sugarcane genotypes were clustered into three major groups, namely, A, B and C (Figure 3). Group B was the largest group with 10 genotypes (55.6\%), followed by Group C with five genotypes (27.8\%) and Group A with three genotypes (16.7\%). Group B was further divided into two sub-groups, BI and BII. The Sub-group BI consisted of two genotypes, GT11 and QT08-558; while the Sub-group BII included eight genotypes. Genotype ROC21 and YT00-236 in Group C were almost genetically identical. In Group B, both ROC25 and YT94-128 and ROC22 and YT60 were genetically close to each other. This was probably due to the fact that ROC-series cultivars of Taiwan were first introduced into Guangdong province, where these cultivars were used either as cross parents to breed the YT-series clones or directly as cultivars if they well adapted to local climates. 


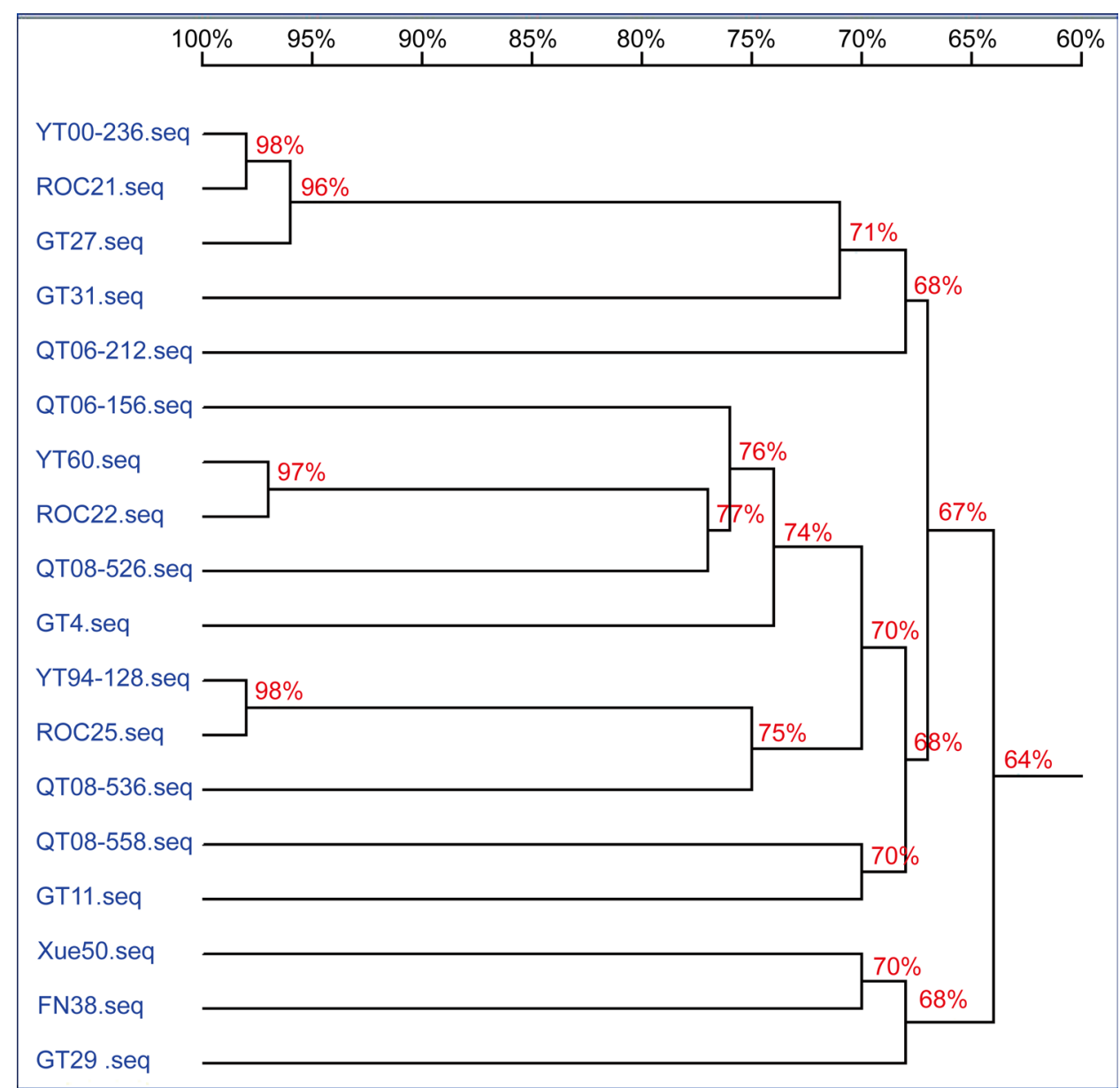

Figure 2. A homology tree of 18 sugarcane genotypes based on SSR marker data.

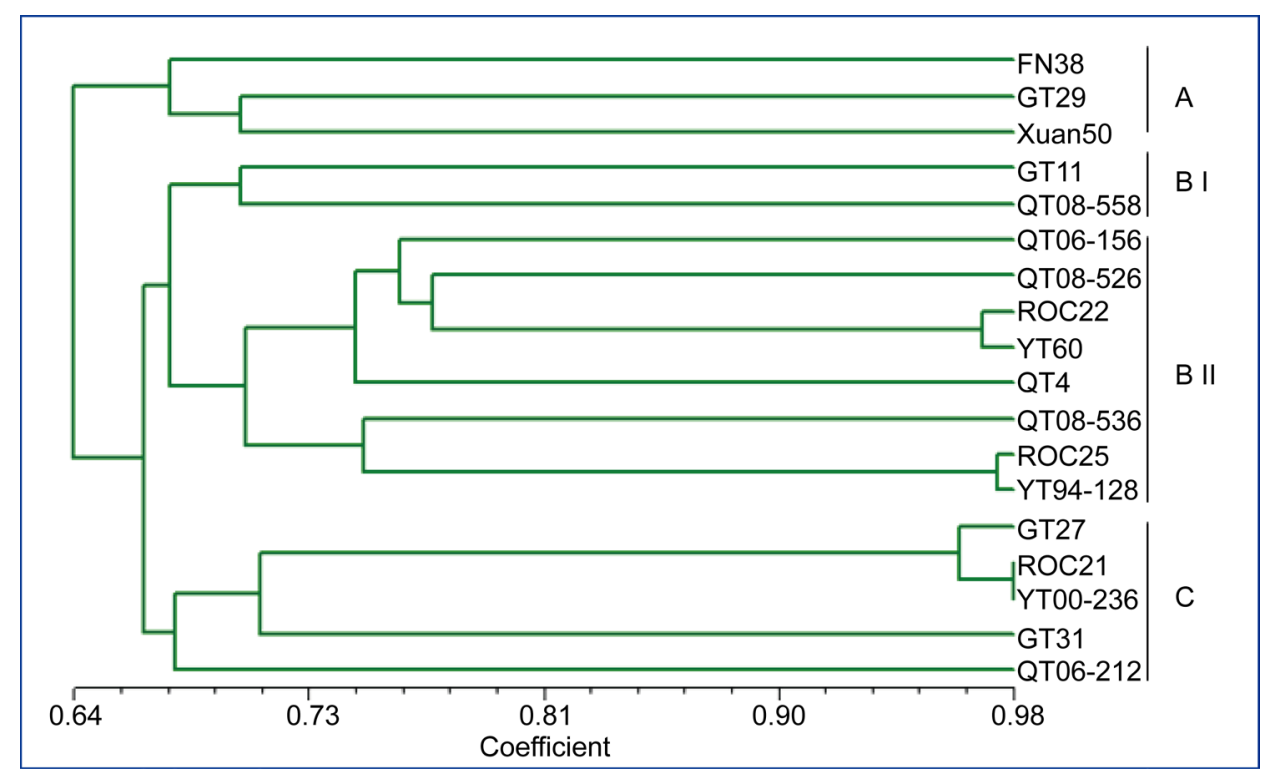

Figure 3. A UPGMA dendrogram showing genetic relationships among 18 sugarcane genotypes based on Jaccard similarity coefficients. 
The 18 sugarcane genotypes did not group in accordance with their geographical origins. One reason might be that these sugarcane genotypes were descendants of the early sugarcane Noblization breeding program, thus, sharing a genetic base of a few common progenitor clones. Our result was in agreement with those from Nair's and Liang's studies [4] [42].

\section{Conclusion}

It is the first report on SSR-based molecular evaluation of genetic variability among sugarcane genotypes from the Karst region of China. All 21 SSR primer pairs were highly polymorphic. Eight SSR primer pairs produced 11 genotype-specific SSR alleles from nine sugarcane genotypes and are capable of distinguishing the nine sugarcane genotypes from one another. Five out of eight SSR primer pairs produced alleles that were unique to the QT-series clones. These eight SSR primer pairs can be very useful in sugarcane variety identity tests. Based on the genetic similarity values, the 18 sugarcane genotypes were clustered into three major groups, but the grouping occurred irrespective of geographical origins. The results from this study help understand the genetic base of sugarcanes germplasm adapted to the Karst region and future assignment of cross parents for the breeding program in Guizhou.

\section{Acknowledgements}

This work was financially supported by Guizhou Agricultural Research Project (No. NY [2013] 3015) and Guizhou Science and Technology Fund (No. [2012] 2253 and No. LKN [2013] 03). The authors are thankful to Dr Yong-Wen Qi from Guangdong Key Lab of Sugarcane Improvement and Bio-Refinery, Guangzhou Sugarcane Industry Research Institute for his help with data analysis.

\section{References}

[1] Pan, Y.-B., Burner, D.M. and Legendre, B.L. (2000) An Assessment of the Phylogenetic Relationship among Sugarcane and Related Taxa Based on the Nucleotide Sequence of $5 \mathrm{~S}$ rRNA Intergenic Spacers. Genetica, 108, 285-295.

http://dx.doi.org/10.1023/A:1004191625603

[2] Jannoo, N., Grivet, L., Seguin, M., Paulet, F., Domaingue, R., Rao, P.S., Dookun, A., D’Hont, A. and Glaszmann, J.C. (1999) Molecular Investigation of the Genetic Base of Sugarcane Cultivars. Theoretical and Applied Genetics, 99, 171-184. http://dx.doi.org/10.1007/s001220051222

[3] Grivet, L., D’Hont, A., Roques, D., Feldmann, P., Lanaud, C. and Glaszmann, J.C. (1996) RFLP Mapping in Cultivated Sugarcane (Saccharum spp.): Genome Organization in a Highly Polypoid and Aneuploid Interspecific Hybrid. Genetics, 142, 987-1000.

[4] Nair, N.V., Selvi, A., Sreenivasan, T.V. and Pushpalatha, K.N. (2002) Molecular Diversity in Indian Sugarcane Cultivars as Revealed by Randomly Amplified DNA Polymorphisms. Euphytica, 127, 219-225. http://dx.doi.org/10.1023/A:1020234428681

[5] Burner, D.M., Pan, Y.-B. and Webster, R.D. (1997) Genetic Diversity of New World and Old World Saccharum Assessed by RAPD Analysis. Genetic Resources and Crop Evolution, 44, 235-240. http://dx.doi.org/10.1023/A:1008631731506 
[6] Pan, Y.-B., Burner, D.M., Ehrlich, K.C., Grisham, M.P. and Wei, Q. (1997) Analysis of Primer-Derived, Non-Specific Amplification Products in RAPD-PCR. BioTechniques, 22, 1072-1074.

[7] Pan, Y.-B., Burner, D.M., Legendre, B.L., Grisham, M.P. and White, W.H. (2004) An Assessment of the Genetic Diversity within a Collection of Saccharum spontaneum with RAPD-PCR. Genetic Resources and Crop Evolution, 51, 895-903. http://dx.doi.org/10.1007/s10722-005-1933-1

[8] Aitken, K.S., Jackson, P.A. and McIntyre, C.L. (2005) A Combination of AFLP and SSR Markers Provides Extensive Map Coverage and Identification of Homo(eo)logous Linkage Groups in a Sugarcane Cultivar. Theoretical and Applied Genetics, 110, 789-801. http://dx.doi.org/10.1007/s00122-004-1813-7

[9] Besse, P., Taylor, G., Carroll, B., Berding, N., Burner, D.M. and McIntyre, C.L. (1998) Assessing Genetic Diversity in a Sugarcane Germplasm Collection Using an Automated AFLP Analysis. Genetica, 104, 143-153. http://dx.doi.org/10.1023/A:1003436403678

[10] Lima, M.L.A., Garcia, A.A.F., Oliveira, K.M., Matsuoka, S., Arizono, H., de Souza Jr., C.L. and de Souza, A.P. (2002) Analysis of Genetic Similarity Detected by AFLP and Coefficient of Parentage among Genotypes of Sugar Cane (Saccharum spp.). Theoretical and Applied Genetics, 104, 30-38. http://dx.doi.org/10.1007/s001220200003

[11] Cordeiro, G.M., Taylor, G.O. and Henry. R.J. (2000) Characterization of Microsatellite Markers from Sugarcane (Saccharum spp.). A Highly Polyploidy Species. Plant Science, 155, 161-168. http://dx.doi.org/10.1016/S0168-9452(00)00208-9

[12] Da Silva J.A.G. (2001) Preliminary Analysis of Microsatellite Markers Derived from Sugarcane Expressed Sequence Tags (ESTs). Genetics and Molecular Biology, 24, 155-159. http://dx.doi.org/10.1590/S1415-47572001000100021

[13] Pan, Y.-B. (2006) Highly Polymorphic Microsatellite DNA Markers for Sugarcane Germplasm Evaluation and Variety Identity Testing. Sugar Tech, 8, 246-256. http://dx.doi.org/10.1007/BF02943564

[14] Pan, Y.-B., Cordeiro, G.M., Richard Jr., E.P. and Henry, R.J. (2003) Molecular Genotyping of Sugarcane Clones with Microsatellite DNA Markers. Maydica, 48, 319-329. http://dx.doi.org/10.2135/cropsci2005.0274

[15] Alwala, S., Suman, A., Arro, J.A., Veremis, J.C. and Kimbeng, C.A. (2006) Target Region Amplification Polymorphism (TRAP) for Assessing Genetic Diversity in Sugarcane Germplasm Collections. Crop Science, 46, 448-455.

[16] Arro, J.A. (2004) Genetic Diversity among Sugarcane Clones Using Target Region Amplification Polymorphism (TRAP) Markers and Pedigree Relationships. Master's Thesis, Louisiana State University, Baton Rouge.

[17] Suhail, K.M., Yadava, S., Srivastava, S., Swapna, M., Chandra, A. and Singh, R.K. (2011) Development and Utilization of Conserved-Intron Scanning Marker in Sugarcane. Australian Journal of Botany, 59, 38-45. http://dx.doi.org/10.1071/BT10188

[18] Chandra, A., Jain, R., Solomon, S., Shrivastava, S. and Roy, A.K. (2013) Exploiting EST Databases for the Development and Characterisation of 3425 Gene-Tagged CISP Markers in Biofuel Crop Sugarcane and Their Transferability in Cereals and Orphan Tropical Grasses. BMC Research Notes, 6, 47. http://dx.doi.org/10.1186/1756-0500-6-47

[19] Cordeiro, G.M., Eliott, F., McIntyre, C.L., Manners, J.M. and Henry, R.J. (2006) Characterization of Single Nucleotide Polymorphisms in Sugarcane ESTs. Theoretical and Applied Genetics, 113, 331-343. http://dx.doi.org/10.1007/s00122-006-0300-8

[20] Devarumath, R., Kalwade, S., Bundock, P., Eliott, F.G. and Henry, R. (2013) Independent 
Target Region Amplification Polymorphism and Single-Nucleotide Polymorphism Marker Utility in Genetic Evaluation of Sugarcane Genotypes. Plant Breeding, 132, 736-747. http://dx.doi.org/10.1111/pbr.12092

[21] Chandra, A., Grisham, M.P. and Pan, Y.-B. (2014) Allelic Divergence and Cultivar-Specific SSR Alleles Revealed by Capillary Electrophoresis Using Fluorescence-Labeled SSR Markers in Sugarcane. Genome, 57, 363-372. http://dx.doi.org/10.1139/gen-2014-0072

[22] Pan, Y.-B., Burner, D.M. and Wei, Q. (2001) Developing Species-Specific DNA Markers to Assist in Sugarcane Breeding. Proceedings of International Society of Sugar Cane Technologists, 24, 337-342.

[23] Selvi, A., Nair, N.V., Noyer, J.L., Singh, N.K., Balasundaram, N., Bansal, K.C., Koundal, K.R. and Mohapatra, T. (2006) AFLP Analysis of the Phenetic Organization and Genetic Diversity in the Sugarcane Complex, Saccharum and Erianthus. Genetic Resources and Crop Evolution, 53, 831-842. http://dx.doi.org/10.1007/s10722-004-6376-6

[24] Maccheroni, W., Jordao, H., De Gaspari, R., De Moura, G.L. and Matsuoka, S. (2009) Development of a Dependable Microsatellite-Based Fingerprinting System for Sugarcane. Proceedings of the International Society of Sugar Cane Technologistics, 27, 47-52.

[25] Oliveira, K.M., Pinto, L.R., Marconi, T.G., Mollinari, M., Ulian, E.C., Chabregas, S.M., Falco, M.C., Burnquist, W., Garcia, A.A. and Souza, A.P. (2009) Characterization of New Polymorphic Functional Markers for Sugarcane. Genome, 52, 191-209.

http://dx.doi.org/10.1139/G08-105

[26] Pinto, L.R., Oliveira, K.M., Ulian, E.C., Garcia, A.A. and Souza, A.P. (2004) Survey in the Expressed Sequence Tag Database (SUCEST) for Simple Sequence Repeats. Genome, 47, 795-804. http://dx.doi.org/10.1139/g04-055

[27] Pinto, L.R., Oliveira, K.M., Marconi, T.G., Garcia, A.F., Ulian, E.C. and Souza, A.P. (2006) Characterization of Novel Sugarcane Expressed Sequence Tag Microsatellites and Their Comparison with Genomic SSRs. Plant Breeding, 125, 378-384.

http://dx.doi.org/10.1111/j.1439-0523.2006.01227.x

[28] Oliveira, K.M., Pinto L.R., Marconi, T.G., Margarido, G.R.A., Pastina, M.M., L.H.M., Teixeira, Figueira, A.V., Ulian, E.C., Garcia, A.A.F. and Souza, A.P. (2007) Functional Integrated Genetic Linkage Map Based on EST-Markers for a Sugarcane (Saccharum spp.) Commercial Cross. Molecular Breeding, 20, 189-208. http://dx.doi.org/10.1007/s11032-007-9082-1

[29] Marconi, T.G., Costa, E.A., Miranda, H.R., Mancini, M.C., Cardoso-Silva, C.B., Oliveira, K.M., Pinto, L.R., Mollinari, M., Garcia, A.A.F. and Souza, A.P. (2011) Functional Markers for Gene Mapping and Genetic Diversity Studies in Sugarcane. BMC Research Notes, 4, 264. http://dx.doi.org/10.1186/1756-0500-4-264

[30] Parida, S.K., Kalia, S.K., Kaul, S., Dalal, V., Hemprapha, G., Selvi, A., Pandit, A., Singh, A., Gaikwad, K., Sharma, T.R., Srivastava, P.S., Singh, N.K. and Mohapatra, T. (2008) Informative Genomic Microsatellite Markers for Efficient Genotyping Application in Sugarcane. Theoretical and Applied Genetics, 118, 327-338. http://dx.doi.org/10.1007/s00122-008-0902-4

[31] Tew, T.L. and Pan, Y.-B. (2010) Microsatellite (Simple Sequence Repeat) Marker-Based Paternity Analysis of a Seven-Parent Sugarcane Polycross. Crop Science, 50, 1401-1408. http://dx.doi.org/10.2135/cropsci2009.10.0579

[32] Sharma, M.D., Dobhal, U., Singh, P., Kumar, S., Gaur, A.K., Singh, S.P., Jeena, A.S., Koshy, E.P. and Kumar, S. (2014) Assessment of Genetic Diversity among Sugarcane Cultivars Using Novel Microsatellite Markers. African Journal of Biotechnology, 13, 1444-1451. http://dx.doi.org/10.5897/AJB2013.13376 
[33] Devarumath, R.M., Kalwade, S.B., Kawar, P.G. and Sushir, K.V. (2012) Assessment of Genetic Diversity in Sugarcane Germplasm Using ISSR and SSR Markers. Sugar Tech, 4, 334344. http://dx.doi.org/10.1007/s12355-012-0168-7

[34] Santos, J.M.D., Filho, L.S.C.D., Soriano, M.L., Silva, P.P.D., Nascimento, V.X., Barbosa, G.V.D.S., Todaro, A.R., Neto, C.E.R.N. and Almeida, C. (2012) Genetic Diversity of the Main Progenitors of Sugarcane from the RIDESA Germplasm Bank Using SSR Markers. Industrial Crops and Products, 40, 145-150. http://dx.doi.org/10.1016/j.indcrop.2012.03.005

[35] Liu, P., Chandra, A., Que, Y., Chen, P.-H., Grisham, M.P., White, W.H., Dalley, C.D., Tew, T.L. and Pan, Y.-B. (2016) Identification of QTLs Controlling Sucrose Content Based on an Enriched Genetic Linkage Map of Sugarcane (Saccharum spp. Hybrids) Cultivar "LCP 85384". Euphytica, 207, 527-549. http://dx.doi.org/10.1007/s10681-015-1538-5

[36] Liu, P., Que, Y. and Pan, Y.-B. (2011) Highly Polymorphic Microsatellite DNA Markers for Sugarcane Germplasm Evaluation and Variety Identity Testing. Sugar Tech, 13, 129-136. http://dx.doi.org/10.1007/s12355-011-0077-1

[37] Pan, Y.-B., Miller, J.D., Schnell, R.J., Richard Jr., E.P. and Wei, Q. (2003) Application of Microsatellite and RAPD Fingerprints in the Florida Sugarcane Variety Program. Sugar Cane International, 19-28.

[38] Pan, Y.-B., Liu, P. and Que, Y. (2014) Independently Segregating Simple Sequence Repeats (SSR) Alleles in Polyploid Sugarcane. Sugar Tech, 17, 235-242. http://dx.doi.org/10.1007/s12355-014-0330-5

[39] Lu, X., Zhou, H., Pan, Y.-B., Chen, C.Y., Zhu, J.-R., Chen, P.-H., Cai, Q. and Chen, R.-K. Segregation Analysis of Microsatellite (SRR) Markers in Sugarcane Polyploids. Genetics and Molecular Research, 14, 18384-18395. http://dx.doi.org/10.4238/2015.December.23.26

[40] Milbourne, D., Meyer, R., Bradshaw, J.E., Baird, E., Bonar, N., Povan, J., Powell, W. and Waugh, R. (1997) Comparison of PCR Based Marker System the Analysis of Genetic Relationships in Cultivated Potato. Molecular Breeding, 3, 127-136. http://dx.doi.org/10.1023/A:1009633005390

[41] Rohlf, F.J. (2000) NTSYS-pc: Numerical Taxonomy and Multivariate Analysis System Version 2.1. Exeter Publishing Setauket, New York.

[42] Pan, Y.-B., Scheffler, B.S. and Richard Jr., E.P. (2007) High-Throughput Genotyping of Commercial Sugarcane Clones with Microsatellite (SSR) DNA Markers. Sugar Tech, 9, 176181.

[43] Hameed, U., Pan, Y.-B., Muhammad, K., Afghan, S. and Iqbal, J. (2012) Use of Simple Sequence Repeat Markers for DNA Fingerprinting and Diversity Analysis of Sugarcane ( Saccharum spp.) Cultivars Resistant and Susceptible to Red Rot. Genetics and Molecular Research, 11, 1195-1204. http://dx.doi.org/10.4238/2012.May.8.1

[44] Liang, J., Pan, Y.-B., Li, Y.-R., Fang, F.-X., Chao, W.-K. and You, J.-H. (2010) Genetic Diversity Assessment of Saccharum Species and Elite Cultivars from China Using SSR Markers. Guihaia, 30, 594-600.

[45] Chen, P.H., Pan, Y.-B., Chen, R.-K., Xu, L.-P. and Chen, Y.-Q. (2009) SSR Marker-Based Analysis of Genetic Relatedness among Sugarcane Cultivars (Saccharum spp. Hybrids) from Breeding Programs in China and Other Countries. Sugar Tech, 11, 347-354. http://dx.doi.org/10.1007/s12355-009-0060-2 
Submit or recommend next manuscript to SCIRP and we will provide best service for you:

Accepting pre-submission inquiries through Email, Facebook, LinkedIn, Twitter, etc. A wide selection of journals (inclusive of 9 subjects, more than 200 journals)

Providing 24-hour high-quality service

User-friendly online submission system

Fair and swift peer-review system

Efficient typesetting and proofreading procedure

Display of the result of downloads and visits, as well as the number of cited articles

Maximum dissemination of your research work

Submit your manuscript at: http://papersubmission.scirp.org/

Or contact ajps@scirp.org 